\title{
RECOVERY OF NITRIC ACID FROM RAFFINATE AND CONDENSATE SOLUTIONS BY STEAM DISTILLATION/PYROHYDROLYSIS AND FRACTIONAL DISTILLATION IN A GLASS COLUMN
}

W. C. Dietrich

\section{UNION CARBIDE}

\section{OAK RIDGE Y-12 PLANT OAK RIDGE, TENNESSEE}




\section{DISCLAIMER}

This report was prepared as an account of work sponsored by an agency of the United States Government. Neither the United States Government nor any agency Thereof, nor any of their employees, makes any warranty, express or implied, or assumes any legal liability or responsibility for the accuracy, completeness, or usefulness of any information, apparatus, product, or process disclosed, or represents that its use would not infringe privately owned rights. Reference herein to any specific commercial product, process, or service by trade name, trademark, manufacturer, or otherwise does not necessarily constitute or imply its endorsement, recommendation, or favoring by the United States Government or any agency thereof. The views and opinions of authors expressed herein do not necessarily state or reflect those of the United States Government or any agency thereof. 


\section{DISCLAIMER}

Portions of this document may be illegible in electronic image products. Images are produced from the best available original document. 
Printed in the United States of America. Available from

National Technical Information Service

U.S. Department of Commerce

5285 Port Royal Road, Springfield, Virginia 22151

Price: Printed Copy \$4.00; Microfiche $\$ 1.45$

This report was prepared as an account of work sponsored by the United States Government. Neither the United States nor the United States Atomic Energy Commission, nor any of their employees, nor any of their contractors, subcontractors, or their employees, makes any warranty, express or implied, or assumes any legal liability or responsibility for the accuracy, completeness or usefulness of any information, apparatus, product or process disclosed, or represents that its use would not infringe privately owned rights. 


\title{
RECOVERY OF NITRIC ACID FROM RAFFINATE AND CONDENSATE SOLUTIONS BY STEAM DISTILLATION/PYROHYDROLYSIS AND FRACTIONAL DISTILLATION IN A GLASS COLUMN
}

\author{
W. C. Dietrich
}

Oak Ridge Y-12 Plant

P.O. Box Y, Oak Ridge, Tennessee 37830

Date Issued - December 28, 1973

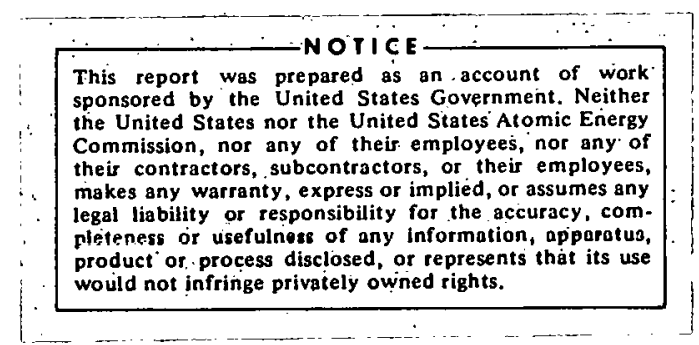

Prepared for the U.S. Atomic Energy Commission Under U.S. Government Contract W.7405eng-26 


\begin{abstract}
Potential processes for the pilot-plant-scale purification and concentration of nitric acid condensate and raffinate solutions were studied. As a result, a process was developed where condensates were continuously purified by an aluminum nitrate-calcium nitrate trap to reduce $200-300-p p m$ fluoride concentrations to less than one ppm. Next, the condensates were fed to an all-glass rectification column to concentrate nitric acid to 14 molar and to reduce 200 - 400-ppm chloride concentrations to less than one ppm. Finally, raffinates were steam distilled and pyrohydrolized to recover greater than 90 percent of the nitrates as nitric acid.
\end{abstract}


CONTENTS

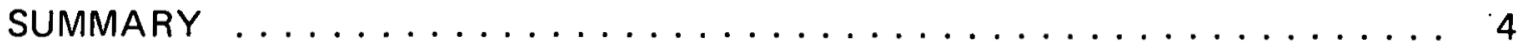

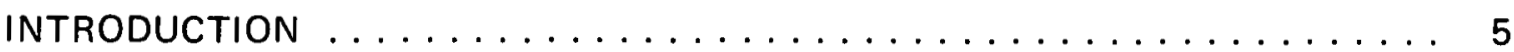

PROCESSING CONDENSATE AND FLUORIDE-CONTAMINATED

FEED AND RAFFINATE SOLUTIONS $\ldots \ldots \ldots \ldots \ldots \ldots \ldots$

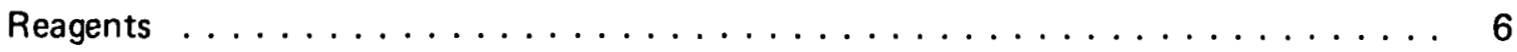

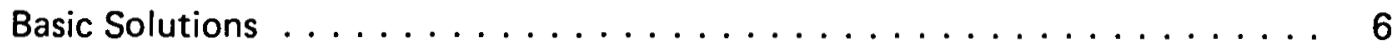

Basic Solids . . . . . . . . . . . . . . . . . . . . 6

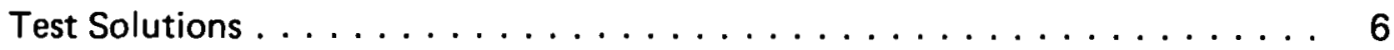

Equipment ............................. 7

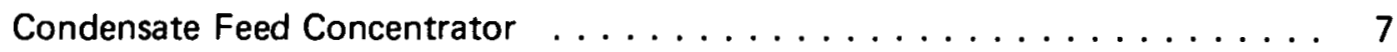

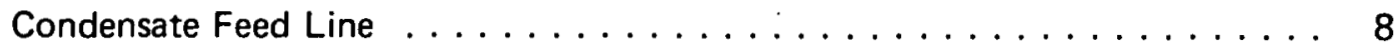

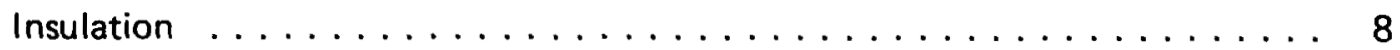

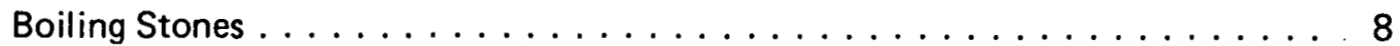

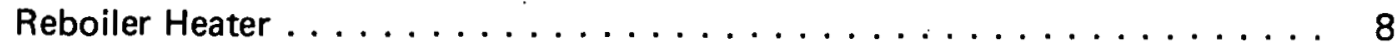

Internal Sampling System . . . . . . . . . . . . . . . . . 8

Chemical Trap Feed and Raffinate Distillation Apparatus . . . . . . . . . 8

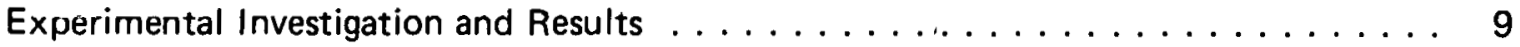

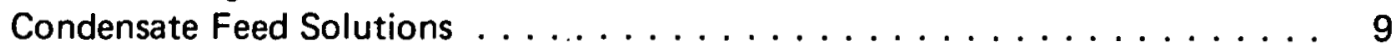

Chemical Trap Feed Solutions . . . . . . . . . . . . . . . . . 11

Raffinate Solutions . . . . . . . . . . . . . . . . . . . 11

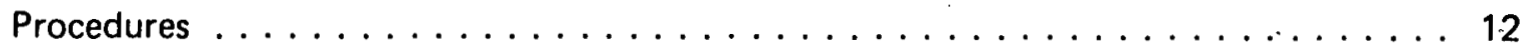

Condensate Feed Solutions . . . . . . . . . . . . . . . . . . 12

Chemical Trap Feed Solutions . . . . . . . . . . . . . . . . . 15

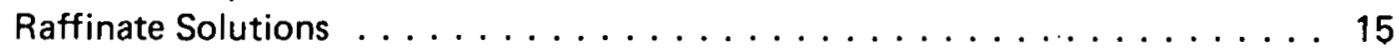

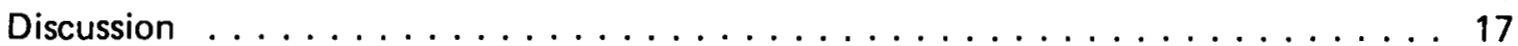

Condensate Feed Solutions . . . . . . . . . . . . . . . . . . . . . . . 17

Chemical Trap Feed Solutions . . . . . . . . . . . . . . . . . . . . . . . 19

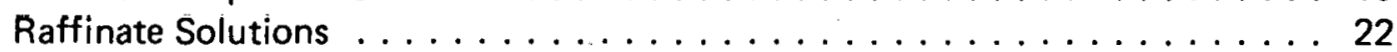

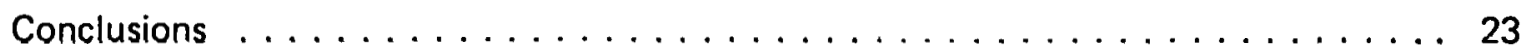

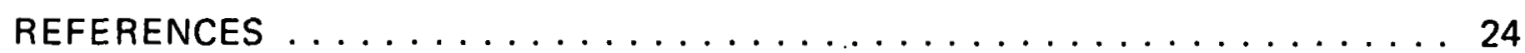




\section{SUMMARY}

Potential processes for the pilot-plant-scale purification and concentration of nitric acid condensates and raffinates were studied. As a result, a process was developed where condensates were continuously purified from fluoride by an aluminum nitrate-calcium nitrate chemical trap. Next, condensates were concentrated and purified from chloride by an all-glass rectification column. Finally, raffinates were steam distilled and pyrohydrolyzed to recover greater than 90 percent of the nitrates as nitric acid.

Condensate solutions containing 1 - 2-molar nitric acid and $200-400-p p m$ chloride ion were concentrated in a glass rectification column to yield $11-14-$ molar nitric acid and $0.2-0.5-\mathrm{ppm}$ chloride ion. Any fluoride in the condensate accumulated in the concentrated nitric acid as hydrofluosilicic acid.

Condensate solutions containing 1-6-molar nitric acid and $200-400$-ppm fluoride ion as hydrofluosilicic acid were passed through the boiling chemical trap solution to yield an average fluoride value of $3 \mathrm{ppm}$ for 1.2 -molar acid, $9.5 \mathrm{ppm}$ for $2.3-\mathrm{molar}$ acid, and $20 \mathrm{ppm}$ for 5.9-molar acid. An addition of 13 grams of aluminun nitrate per liter to the original condensate solution yielded an average fluoride value of $0.5 \mathrm{ppm}$ for 1 -molar acid, $0.3 \mathrm{ppm}$ for 3-molar acid, and $1.6 \mathrm{ppm}$ for 6-molar acid. A 1.03-molar condensate solution, spiked with $22 \mathrm{ppm}$ of uranium as the uranyl ion, was passed through the trap solution to yield a distillate solution with no detectable uranium.

An estimate of the average acidity of the chemical trap for three feed solutions revealed a 0.39-molar liquid phase/1.2b-molar vapor phase for the 1.03-molar feed, a 0.86-mular liquid phase/2.66-molar vapor phase for the 3.01-molar feed, and a 1.73-molar liquid phase/5.85-molar vapor phase for the 6.10-molar feed.

Raffinates containing 0.80 -molar aluminum nitrate, 0.10 - 0.37-molar calcium nitrate, 0.19 - 0.74-molar hydrofluosilicic acid, and 3.41-molar nitric acid were steam distilled and pyrohydrolyzed to recover more than 90 percent of all nitrate ion as nitric acid. Distillation was essentially complete without heating the residue above $240^{\circ} \mathrm{C}$. Most of the nitrates in an original 20-milliliter sample were recovered as nitric acid withln 168 milliliters of distillate, with an average fluoride contamination of $18-37$ parts per million. 


\section{INTRODUCTION}

Uranium refining in process solutions involves extracting the uranium into an organic solvent from a nitric acid raffinate solution, recovering the purified uranium in a water backwash, and evaporating the backwash to concentrate the uranium. This uranium refining process also yields a strong nitric acid raffinate and a dilute nitric acid condensate solution with low concentrations of chloride and fluoride, and disposal of these solutions must be made.

Distillation appeared to be the most practical scheme for removing nitric acid from these condensate and raffinate solutions. In the case of condensates, previous efforts to purify and concentrate nitric acid in a stainless steel rectification column resulted in destructive corrosion of the column by chlorides and fluorides accumulating in the column. If fluoride could be removed, then an all-glass rectification column should remove chlorides from concentrated nitric acid. In the case of raffinates, distillation should separate nitric acid from any salts, and the resulting distillate could be processed as condensates.

An investigation was initiated at the Oak Ridge $Y-12$ Plant (a) to explore the rectification behavior of nitric acid solutions in an all-glass column, the depletion of fluoride from nitric acid solutions by an aluminum nitrate and/or calcium nitrate trap, and the separation of nitrates as nitric acid from raffinate solutions by steam distillation and pyrohydrolysis.

(a) Operated by the Union Carbide Corporation's Nuclear Division for the US Atomic Energy Commission. 


\section{PROCESSING CONDENSATE AND FLUORIDE-CONTAMINATED FEED AND RAFFINATE SOLUTIONS}

\section{REAGENTS}

\section{Basic Solutions}

Nitric Acid, Concentrated-Reagent ACS grade at a concentration of $70-71$ percent hydrogen nitrate.

Hydrofluoric Acid, Concentrated - Reagent ACS grade at a concentration of 48 percent hydrngen tluoride.

Hydrochloric Acid, Dilute - One molar certified.

Sodium Hydroxide, Dilute - One-tenth molar certified.

Methyl-Purple Indicator - Premix solution.

\section{Básic Solids}

Calcium Nitrate, Quadrihydrate - Reagent ACS grade.

Aluminum Nitrate, Nonahydrate - Reagent ACS grade.

Sodium Fluoride - Reagent ACS grade.

UranyI Nitrate, Hexahydrate - Reagent ACS grade.

\section{Test Solutions}

Condensate Feed Solution A - Mix one liter of water, 284 milliliters of concentrated nitric acid, 11.3 milliliters of one-molar hydrochloric acid, 0.4423 gram of sodium fluoride, and enough additional water to make two-liters of solution. Store in a plastic bottle.

Condensate Feed Solution B - Mix one liter of water, 284 milliliters of concentrated nitric acid, 22.6 milliliters of one-molar hydrochloric acid, 1.7684 grams of sodium fluoride, and enough additional water to make two liters of solution. Store in a plastic bottle.

Still Liquid - Mix 649 milliliters of concentrated nitric acid and enough water to make one liter of solution.

Feed Solution 1 - Mix one liter of water, 194 milliliters of concentrated nitric acid, 0.8843 gram of sodium fluoride, and enough additional water to make two liters of solution. Store in a plastic bottle.

Feed Solution 2 - Mix one liter of water, 129 milliliters of concentrated nitric acid, 1.7684 grams of sodium fluoride, and enough additional water to make two liters of solution. Store in a plastic bottle. 
Feed Solution 3 - Mix one liter of water, 387 milliliters of concentrated nitric acid, 1.7684 grams of sodium fluoride, 0.0928 gram of uranyl nitrate, and enough additional water to make two liters of solution. Store in a plastic bottle.

Feed Solution 4 - Mix one liter of water, 774 milliliters of concentrated nitric acid, 1.7684 grams of sodium fluoride and enough additional water to make two liters of solution. Store in a plastic bottle.

Feed Solution-Aluminum Series - Repeat Feed Solutions 2 through 4 and add 26 grams of aluminum nitrate to each solution. Store in plastic bottles.

Chemical Trap Solution $X$ - Mix 1,125 grams of hydrated aluminum nitrate, 65 milliliters of concentrated nitric acid, and enough water to make one liter of solution.

Chemical Trap Solution Y - Mix 985 grams of hydrated calcium nitrate with 65 milliliters of concentrated nitric acid. Heat to melt the salt, then add enough water to make one liter of solution.

Chemical Trap Solution Z - Mix 546 grams of hydrated calcium nitrate, 246 grams of hydrated aluminum nitrate, and 14 milliliters of concentrated nitric acid, then heat the mixture to melt the salts.

Raffinate Solution 1 - Mix 300 grams of hydrated aluminum nitrate, 87 grams of hydrated calcium nitrate, 31 milliliters of hydrofluoric acid, 227 milliliters of concentrated nitric acid, and enough water to make one liter of solution. Store in a plastic container.

Raffinate Solution 2 -Mix 300 grams of hydrated aluminum nitrate, 8 milliliters of concentrated hydrofluoric acid, 227 milliliters of concentrated nitric acid, and enough water to make one liter of solution. Store in a plastic container.

\section{EQUIPMENT}

\section{Condensate Feed Concentrator}

The glass fractional distillation column was insulated and consisted of a reboiler, packed column, condenser, reflux-distillate distributor, and four Teflon sampling tubes, as illustrated in Figure 1. The reboiler was a Glas-Col-heated, one-liter, three-necked flask with an eight-inch looped-side-arm product take off. The principle column was a 14-inch-long by 2-inch-diameter Pyrex tube, packed at one time with 1/4-inch-long by $1 / 4$-inch-diameter glass tubes and at another time with single-turn glass helixes of $1 / 8$-inch-inner-diameter holes. Another column, 28 inches long and packed with helixes, was also constructed. Both columns were sealed at the top by a rubber stopper wrapped in Teflon film to provide coupling of the external and internal systems. The condenser was of the Liebig type and permitted the condensate to discharge into a $Y$ section where part of the condensate was recycled through a valve-controlled eight-inch loop back to the head of the column, and part was removed as distillate. 


\section{Condensate Feed Line}

A flexible, 1/4-inch-diameter, Tygon tube was connected to the column feed input and passed through a Sigmamotor pump to a sample reservoir. The pump was controlled by a Zeromax variable speed reducer.

\section{Insulation}

The columns, condenser input tube, and upper half of the reboiler were covered with three layers of 1/8-inch-thick Fiberfrax paper.

\section{Boiling Stones}

Greenlite 30 insulating fire brick, broken into $1 / 2$-inch pieces, was used.

\section{Reboiler Hoater}

The bottom half of a Glas-Col heater for a three-liter flask was used. The heater was powered by a 10-ampere, 0 - 140-volt variable autotransformer.

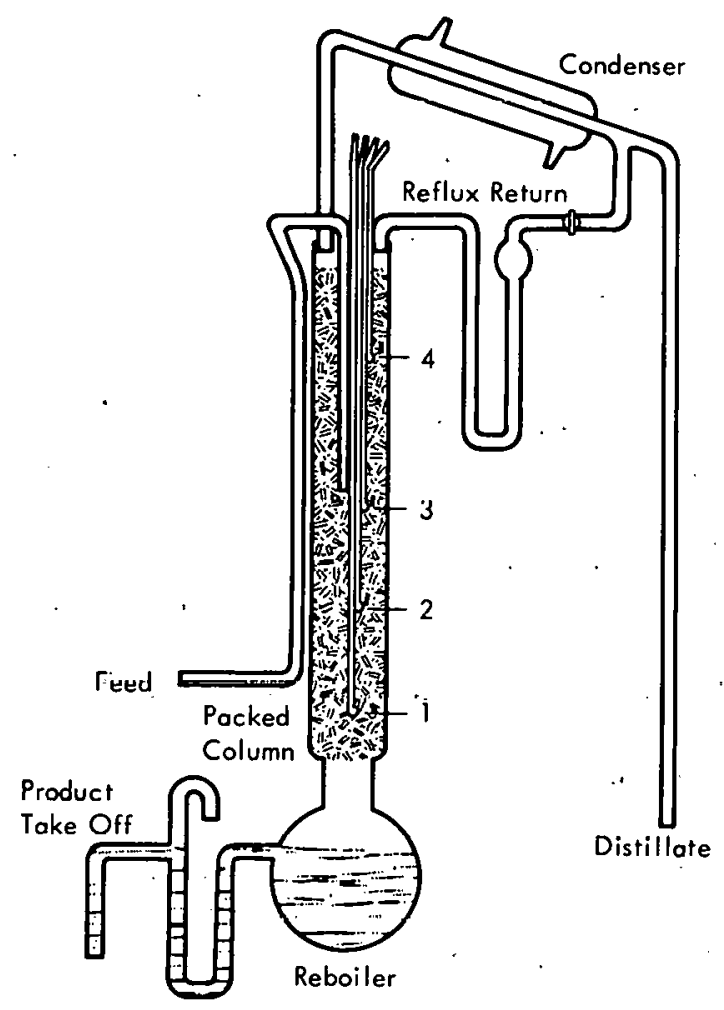

Figure 1. DISTILLATION COLUMN FOR CONDENSATES.

\section{Internal Sampling System}

The column bed was sampled along its central axis by four, $1 / 8$-inch-outside-diameter Teflon tubes which passed through a stopper in the column. The external end of each tube was passed through a Size 3 rubber stopper, which was then inserted into a 25-milliliter flask with a side arm. Inside each flask was a 15-millimeter-diameter by 45 -millimeter-long glass vial that received sample solution when a slight vacuum was applied to the side arm of the flask.

\section{Chemical Trap Feed and Raffinate Distillation Apparatus}

An apparatus was assembled which consisted of a reaction' tube, tubing furnace, boiler with oxygen sweep, acid feed, spray trap, water-cooled condenser, Vitrosil reaction boat, and thermocouple detector with meter (see Figure 2). The reaction tube was a piece of quartz, $13 / 8$ inches in diameter by 37 inches long, which was fitted with ball-joint connectors and heated by a Hevi-Duty organic multiple-unit clam-shell electric furnace. The boiler was a one-liter, three-necked, round-bottom flask, filled with about 500 milliliters of water or trap solution, and heated by an electric mantle. Oxygen was bubbled through the boiler liquid to sweep vapor through the quartz tube into the condenser. A spray trap was incorporated into the boiler vapor outlet line to retain the trap solution. A detailed enlargement of the spray trap is deplicted in Figure 3. 


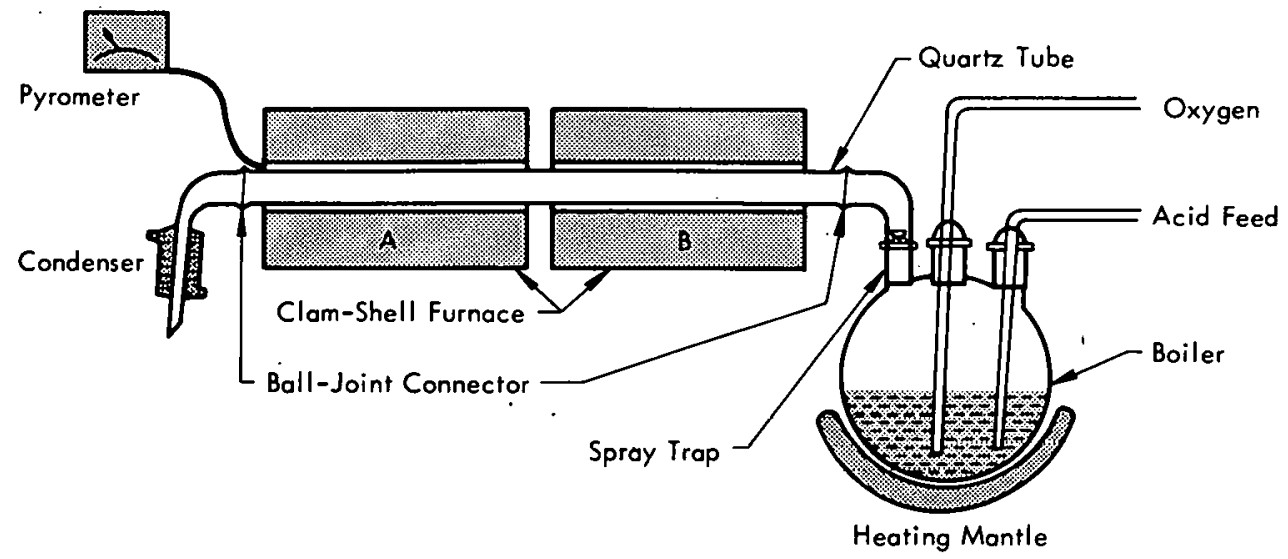

Figure 2. CHEMICAL TRAP AND A DISTILLATION/PYROHYDROLYSIS APPARATUS FOR FEED AND RAFFINATE SOLUTIONS.

The acid feed line to the boiler was replaced with a stopper and the boiler charged with about $\mathbf{5 0 0}$ milliliters of water when raffinate samples were processed. The raffinate sample was placed in a 1/4-inch-wide by $1 / 2$-inch-high by 6 -inch-long Vitrosil boat inserted into the quartz tube in a region near the center of Furnace $A$.

\section{EXPERIMENTAL INVESTIGA- TION AND RESULTS}

\section{Condensate Feed Solutions}

The fractional distillation column was packed with Raschig rings and set into continuous operation to process Condensate Solution A according to the procedure. When the nitric acid concentration in the distillate reached 4.0 molar for one run and 0.32 molar for another run, samples of the distillate, inner column solutions, and still liquid were taken. These samples were then analyzed for nitric acid and chloride. The results are presented in Table 1.

The fractional distillation column was repacked with helixes, and continuous operation was permitted until the nitric acid concentration in the distillate was 0.14 molar for one run and 0.008 molar for another run. Samples from the distillate, inner column solutions,' and still liquid

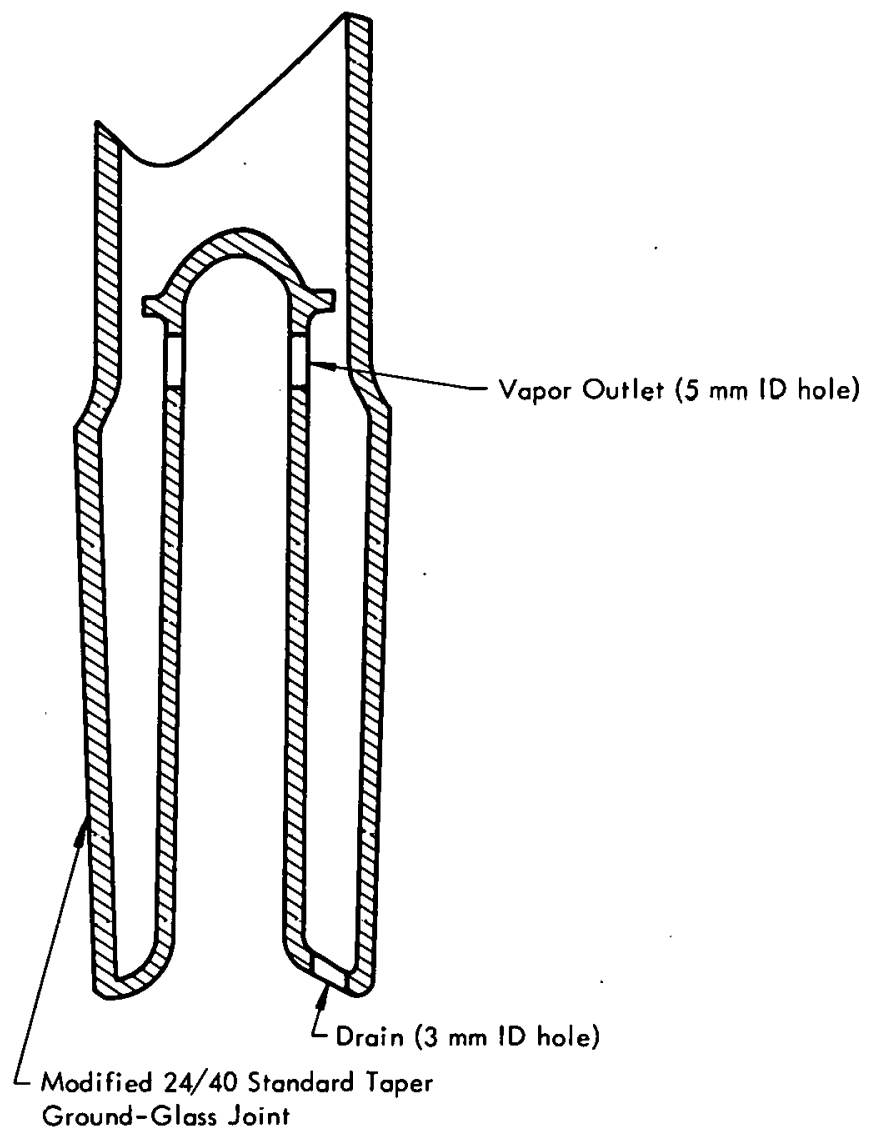

Figure 3. DETAILED ENI.ARGEMENT OF THE SPRAY TRAP SEEN IN FIGURE 2. 
Table 1

DISTRIBUTION OF CHLORIDE AND FLUORIDE IN NITRIC ACID CONCENTRATOR

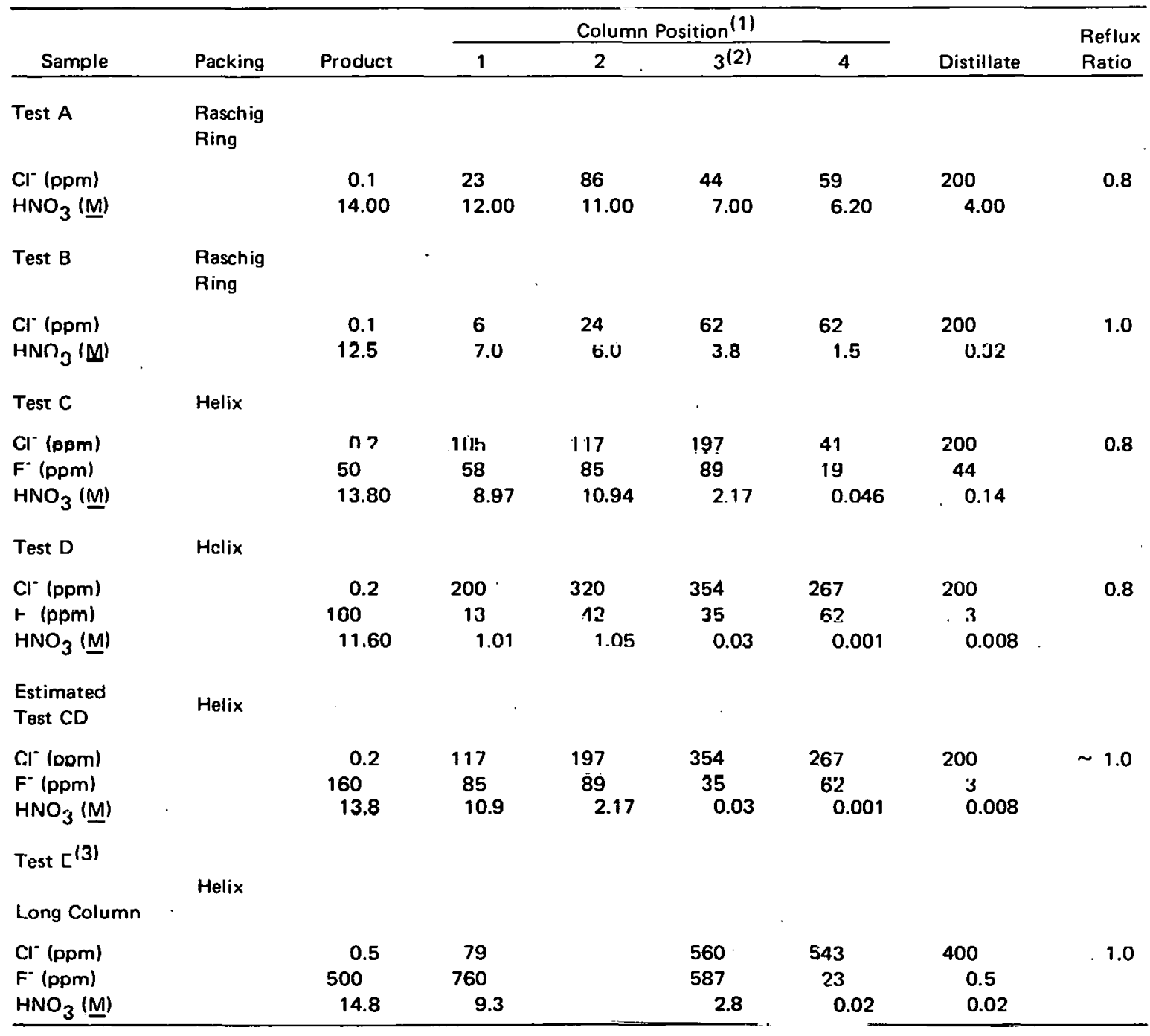

(1) See Figure 1 for location of column position.

(2) Added $2.2 \mathrm{M} \mathrm{HNO}_{3}$ condensate solution containing $200 \mathrm{ppm} \mathrm{Cl}-$ and $100 \mathrm{ppm} \mathrm{r}$.

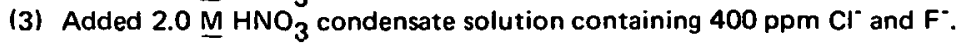

were taken from each run and were analyzed for nitric acid, chlorlde, and fluoride cuntent (Table 1).

An estimation of the rectification power of the packed columns revealed about 2.5 plates for the Raschig ring packing and about 4.0 plates for the Helix packing. Results from both helix-packed columns were combined to estimate the performance of a hypothetical longer column (Table 1).

A helix-packed column of twice the length of the "real" column was permitted to process Condensate Solution B until the nitric acid concentration in the distillate was 0.02 molar. Samples from the system were then analyzed for nitric acid, chloride, and fluoride. These results are also presented in Table 1. 


\section{Chemical Trap Feed Solutions}

The boiler flask was charged with 300 milliliters of Trap Solution $X$ for one run and Trap Solution $Y$ for another run to process Chemical Trap Feed Solution 1 according to the procedure. Distillate from the boiler was collected in 55-milliliter fractions and analyzed for nitric acid and fluoride content. The results of these analyses are presented in Tables 2 and 3.

Trap Solutions $X$ and $Y$ were each spiked with various amounts of sodium fluoride, heated to boiling, and distillate samples collected for fluoride analysis. The results of these analyses are presented in Table 4.

The boiler was charged with 450 milliliters of Trap Solution Z, and Feed Solutions 2, 3, and 4 were cycled through the trap solution. Distillate from the boiler was collected in 55-milliliter fractions and analyzed for nitric acid and fluoride content. The results of these analyses are presented in Table 5. An account was made of all nitric acid entering and leaving the trap solution to estimate the average acid content of the liquid and vapor phase of the trap. The results of this accountability are presented in Table 6.

Feed Solutions 2, 3, and 4 were each spiked with 13 grams of aluminum nitrate per liter and were cycled through 450 milliliters of Trap Solution $Z$. Distillate from the trap was collected in 55-milliliter fractions and analyzed for nitric acid and fluoride content. Results from these analyses are summarized in Table 7.
Table 2

DEPLETION OF FLUORIDE ION IN A NITRIC ACID FEED SOLUTION BY A THREEE MOLAR ALUMINUM NITRATE IN ONE MOLAR NITRIC ACID TRAP SOLUTION (Trap Solution $X$ )

\begin{tabular}{ccc}
\hline $\begin{array}{c}\text { Trap Output } \\
\text { Fractions Analyzed } \\
(55 \mathrm{~m} / \mathrm{s} \text { each) }\end{array}$ & $\begin{array}{c}\text { Nitric Acid } \\
\text { Concentration } \\
(\mathrm{M})\end{array}$ & $\begin{array}{c}\text { Fluoride Ion } \\
\text { Concentration } \\
\text { (ppm) }\end{array}$ \\
\hline 1 & 1.10 & $<0.4$ \\
2 & 1.13 & $<1$ \\
6 & 1.50 & $<1$ \\
9 & 1.53 & 0.4 \\
12 & 1.40 & 0.6 \\
15 & 1.62 & 1.7 \\
18 & 1.47 & 0.7 \\
21 & 1.33 & 1.4 \\
24 & 1.53 & 2.2 \\
27 & 1.33 & 1.4 \\
30 & 1.50 & 1.6 \\
33 & 1.43 & 2.9 \\
35 & 1.50 & 3.6 \\
\hline
\end{tabular}

(1) Trap Input - 1.5-M nitric acid containing 200-ppm fluoride ion.

Table 3

DEPLETION OF FLUORIDE ION IN A NITRIC ACID FEED SOLUTION BY A SIX MOLAR CALCIUM NITRATE IN ONE-MOLAR ACID TRAP SOLUTION (Trap Solution $Y$ )

\begin{tabular}{ccc}
\hline $\begin{array}{c}\text { Trap Output } \\
\text { Fractions Analyzed } \\
(55 \text { mis each) }\end{array}$ & $\begin{array}{c}\text { Nitric Acid } \\
\text { Concentration } \\
\text { (M) }\end{array}$ & $\begin{array}{c}\text { Fluroide Ion } \\
\text { Concentration } \\
\text { (ppm) }\end{array}$ \\
\hline 1 & 1.80 & 11.7 \\
3 & 1.00 & 20.6 \\
6 & 1.43 & 24.0 \\
9 & 1.70 & 21.5 \\
12 & 1.80 & 22.0 \\
16 & 1.63 & 22.4 \\
19 & 1.63 & 22.4 \\
22 & 1.53 & 25.6 \\
25 & 1.33 & 23.3 \\
28 & 1.60 & 22.5 \\
31 & 1.37 & 22.4 \\
34 & 1.43 & 2.34 \\
\hline
\end{tabular}

(1) Trap Input - 1.5-M nitric acid containing 200-ppm fluoride ion.

\section{Raffinate Solutions}

Samples containing 20 milliliters each of Raffinate Solutions 1 and 2 were steam distilled and pyrohydrolyzed according to the developed procedure. The temperature of the sample 
Table 4

CAPACITY OF ALUMINUM AND CALCIUM CHEMICAL TRAP SOLUTIONS FOR FLUORIDE ION

\begin{tabular}{lcc}
\hline & \multicolumn{2}{c}{ Fluoride lon Concentration (ppm) } \\
\cline { 2 - 3 } Sample & Trap Solution & Distillate Solution \\
\hline Al-Trap-1 & 2,570 & 1.4 \\
Al-Trap-2 & 5,140 & 3.5 \\
Al-Trap-3 & 10,280 & 5.7 \\
& & \\
Ca-Trap-1 & 2,000 & 22.0 \\
Ca-Trap-2 & 5,000 & 16.8 \\
Ca-Trap-3 & 10,000 & 14.9 \\
Ca-Trap-4 & 20,000 & 14.7 \\
\hline
\end{tabular}

area was monitored during this treatment (Figure 4). The distillate was recovered in 21-milliliter fractions and each fraction was analyzed for its fluoride and nitric acid content. Results from these analyses are recorded in Tables 8 and 9 and are depicted graphically in Figures 5 and 6.

Recovery of total nitrate from the raffinate solutions was about 100 percent. A choice of maximum nitrate recovery with minimum fluoride contamination was arbitrarily selected at 168

milliliters of distillate to yield 88 percent nitrate from Sample 1 and 95 percent nitrate from Sample 2 (Tables 8 and 9 and Figures 5 and 6).

\section{PROCEDURES}

\section{Condensate Feed Solutions}

Steps in the recovery of nitric acid from condensate feed solutions are as follows:

1. Turn on the water to the condenser.

2. Adjust the Sigmamotor pump to permit a condensate flow rate of about 130 milliliters per.hour, then shut off the pump and connect the output of the primed condensate line to the column input.

3. Add about 200 grams of boiling stones to the reboiler, fill the reboiler with still liquid until the side arm just overflows, connect the Glass-Col reboiler heater circuit to the Variac, and adjust the Variac to 110 volts.

4. Turn on the Varıac and permit the still liquid to boil.

5. When distillate first appears, turn on the pump, shut off the valve in the reflux loop, and measure the total condensate flow rate. (The condensate flow rate should be about twice the rate of the condensate feed rate; if not, then adjust the reboiler heater accordingly and adjust the valve in the reflux loop to permit the distillate to equal the condensate feed flow rate. The column is now set for continuous operation.)

6. Occasionally sample the distillate, still liquid, and internal solutions. Retain these samples for analysis.

7. Estimate the performance of the system by determining the nitric acid concentration in the distillate by alkalimetric titration with standard sodium hydroxide using methyl-purple indicator. (Please note that the sampling procedures are highly subject to change with the purpose of the experiment.) 
Table 5

CONTINUOUS DEPLETIONS OF THE FLUORIDE ION IN FEED SOLUTIONS CYCLING FROM ONE TO SIX MOLAR NITRIC ACID BY AN ALUMINUM-CALCIUM NITRATE TRAP SOLUTION

\begin{tabular}{|c|c|c|c|c|c|c|c|c|c|c|c|}
\hline \multirow{2}{*}{$\begin{array}{l}\text { Trap Output } \\
\text { Fractions Analyzed } \\
\text { (55 mls each) }\end{array}$} & \multicolumn{2}{|c|}{$\begin{array}{l}\text { Nitric Acid } \\
\text { Concentration } \\
\text { (M) }\end{array}$} & \multirow{2}{*}{$\begin{array}{c}\text { Fluoride } \\
\text { lon } \\
\text { Concentration (1) } \\
\text { (ppm) }\end{array}$} & \multirow{2}{*}{$\begin{array}{c}\text { Trap Output } \\
\text { Fractions Analyzed } \\
\text { (55 mls each) }\end{array}$} & \multicolumn{2}{|c|}{$\begin{array}{c}\text { Nitric Acid } \\
\text { Concentrations } \\
\text { (M) }\end{array}$} & \multirow{2}{*}{$\begin{array}{c}\text { Fluorida } \\
\text { lon } \\
\text { Concentration } \\
\text { (ppm) }\end{array}$} & \multirow{2}{*}{$\begin{array}{c}\text { Trap Output } \\
\text { Fractions Analyzed } \\
(55 \mathrm{~m} / \mathrm{s} \text { each })\end{array}$} & \multicolumn{2}{|c|}{$\begin{array}{l}\text { Nitric Acid } \\
\text { Concentrations } \\
\text { (M) }\end{array}$} & \multirow{2}{*}{$\begin{array}{c}\begin{array}{c}\text { Fluoride } \\
\text { lon } \\
\text { Concentration (1) } \\
\text { (ppm) }\end{array} \\
\end{array}$} \\
\hline & Feed & Distillate & & & Feed & Distillate & & & $\overline{\text { Feed }}$ & Distillate & \\
\hline \multirow[t]{2}{*}{2} & 1.03 & 1.70 & & 22 & 3.01 & 1.70 & & 42 & 6.10 & 2.90 & \\
\hline & & & & & & & & 43 & 6.10 & 4.25 & 16.2 \\
\hline 3 & 1.03 & 1.43 & & 23 & 3.01 & 2.24 & & 44 & 6.10 & 4.90 & \\
\hline 4 & 1.03 & 1.20 & & 24 & 3.01 & 2.32 & & 45 & 6.10 & 5.45 & \\
\hline 7 & 1.03 & 1.00 & & 26 & 1.03 & 2.72 & & & & & \\
\hline 8 & 1.03 & 1.04 & & 27 & 1.03 & 2.24 & 3.7 & $\begin{array}{l}48 \\
49\end{array}$ & $\begin{array}{l}1.03 \\
1.03\end{array}$ & $\begin{array}{l}5.80 \\
4.41\end{array}$ & \\
\hline 9 & 1.03 & 1.08 & & 28 & 1.03 & 1.82 & & 50 & 1.03 & 3.02 & 5.9 \\
\hline \multirow[t]{2}{*}{10} & 1.03 & 1.05 & 2.2 & 29 & 1.03 & 1.60 & & 51 & 1.03 & 2.28 & \\
\hline & & & & 30 & 1.03 & 1.44 & 6.2 & 52 & 1.03 & 1.82 & 5.4 \\
\hline 11 & 3.01 & 1.13 & & 31 & 3.01 & 1.40 & & 53 & 3.01 & 2.02 & \\
\hline 12 & 3.01 & 1.78 & & 32 & 3.01 & 1.85 & & 54 & 3.01 & 2.20 & \\
\hline 18 & 1.03 & 1.61 & & 38 & 1.03 & 1.75 & 3.6 & 60 & 1.03 & 1.34 & 3.2 \\
\hline 19 & 1.03 & 1.39 & & 39 & 1.03 & 1.56 & & 61 & 1.03 & 1.30 & \\
\hline 20 & 1.03 & 1.23 & 2.6 & 40 & 1.03 & 1.40 & 3.6 & 62 & 1.03 & 1.18 & 3.4 \\
\hline
\end{tabular}

(1) Fluoride ion in the feed solutions was fixed at $\mathbf{4 0 0} \mathrm{ppm}$. 
Table 6

ESTIMATE OF NITRIC ACID CONCENTRATIONS IN THE NITRATECALCIUM NITRATE TRAP CYCLED WITH ONE TO SIX MOLAR NITRIC
ACID FEED SOLUTIONS

\begin{tabular}{|c|c|c|c|}
\hline \multirow{2}{*}{$\begin{array}{l}\text { Cycled } \\
\text { Sample } \\
\end{array}$} & \multicolumn{3}{|c|}{ Average Nitric Acid Concentration (M) } \\
\hline & Feed & Trap Vapor & Trap Liquid \\
\hline$\frac{1}{1}$ & & 1.04 & 0.24 \\
\hline 2 & 1.03 & 1.23 & 0.38 \\
\hline 3 & 1.03 & 1.44 & 0.46 \\
\hline 4 & 1.03 & 1.40 & $\underline{0.48}$ \\
\hline Average & & 1.25 & 0.39 \\
\hline 1 & 3.01 & 2.72 & 0.74 \\
\hline 2 & 3.01 & 2.59 & 0.92 \\
\hline 3 & 3.01 & 2.67 & 0.91 \\
\hline Average & & 2.66 & 0.86 \\
\hline 1 & 6.10 & 5.85 & 1.73 \\
\hline
\end{tabular}

Table 7

CONTINUOUS DEPLETION OF FLUOROALUMINATE ION IN FEED

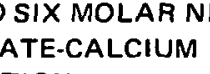

NITRATE TRAP SOLUTION

\begin{tabular}{ccc}
\hline Trap Output & $\begin{array}{c}\text { Nltrlc Acld } \\
\text { Concentration }(M)\end{array}$ & $\begin{array}{c}\text { Fluoplde Ion } \\
\text { concentration (1) }\end{array}$ \\
Fractions Analyzed &
\end{tabular}

Fractions Analyzed Clluorlde lon
Concentration $(M)$
Concentration (65 mls cach) Feed Distillate (ppm)

\begin{tabular}{rlll}
1 & 1.03 & 2.17 & 0.35 \\
4 & 1.03 & 1.40 & 0.60 \\
6 & 1.03 & 1.92 & 0.80 \\
9 & 3.01 & 2.37 & 0.30 \\
12 & 3.01 & 2.94 & 0.35 \\
15 & 1.03 & 1.63 & 0.65 \\
18 & 1.03 & 1.09 & 0.55 \\
21 & 6.10 & 4.30 & 2.00 \\
23 & 6.10 & 5.60 & 2.15 \\
26 & 6.10 & 6.03 & 0.65 \\
29 & 1.03 & 3.56 & 0.35 \\
31 & 1.03 & 1.68 & 0.30 \\
34 & 1.03 & 1.32 & 0.30 \\
37 & 3.01 & 2.39 & 0.30 \\
40 & 3.01 & 2.99 & 0.25 \\
43 & 1.03 & 1.76 & 0.75 \\
46 & 1.03 & 1.30 & 0.55 \\
\hline
\end{tabular}

(1) Fluoride ion concentration in the feed solution was $400 \mathrm{ppm} F$ as fluoroaluminate.
Table 8

STEAM DISTILLATION/PYROHYDROLYSIS RESULTS

\begin{tabular}{|c|c|c|c|}
\hline $\begin{array}{l}\text { Distillatat } \\
\text { Fractions }\end{array}$ & $\begin{array}{c}\text { Accumulated } \\
\text { Volume } \\
\text { (imils) }\end{array}$ & $\begin{array}{c}\text { Fluoride } \\
\text { Concentration } \\
\text { (ppini) }\end{array}$ & $\begin{array}{l}\text { Nitric Acid } \\
\text { Concentration } \\
(\%)\end{array}$ \\
\hline 1 & 21 & 33 & 0.51 \\
\hline 2 & 42 & 48 & 1.30 \\
\hline 3 & 63 & 60 & 2.80 \\
\hline 4 & 84 & 65 & 6.01 \\
\hline 5 & $105^{(1)}$ & 55 & .12 .03 \\
\hline 6 & 126 & 13 & 8.39 \\
\hline & 147 & 5 & 2.88 \\
\hline 8 & 168 & 13 & 1.30 \\
\hline & 189 & 94 & 2.90 \\
\hline 10 & 210 & 264 & 2.04 \\
\hline 11 & 231 & 970 & ก. 28 \\
\hline 12 & 252 & 1,867 & 0.29 \\
\hline
\end{tabular}

(11) Sample aliquant became just moist.
Toblo 0

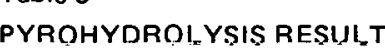
FOR RAFFINATE SAMPLE 2

\begin{tabular}{cccc}
\hline $\begin{array}{c}\text { Distillate } \\
\text { rractions }\end{array}$ & $\begin{array}{c}\text { Accumulated } \\
\text { Volumg } \\
\text { (mls) }\end{array}$ & $\begin{array}{c}\text { Fluoride } \\
\text { concentration } \\
\text { (ppm) }\end{array}$ & $\begin{array}{c}\text { Nitric Acid } \\
\text { Concentration } \\
(\% \%)\end{array}$ \\
\hline 1 & 21 & 22 & 0.43 \\
2 & 42 & 7 & 1.53 \\
3 & 63 & 9 & 3.45 \\
4 & 84 & 10 & 8.33 \\
5 & 105 & 7 & 13.31 \\
6 & 126 & 4 & 7.51 \\
7 & 147 & 14 & 1.97 \\
8 & 168 & 73 & 0.94 \\
9 & 189 & 635 & 0.28 \\
10 & 210 & 1.466 & 0.09 \\
11 & 231 & 822 & 0 \\
12 & 252 & 275 & 0 \\
\hline
\end{tabular}

(1) Sample aliquant became just moist. 


\section{Chemical Trap Feed Solutions}

Steps in the recovery of nitric acid from chemical trap feed solutions are as follows:

1. Turn on Furnaces $A$ and $B$ to low intensity and permit the furnaces to come to a temperature of about $200^{\circ} \mathrm{C}$.

2. Turn on the water to the condenser, and add about 500 milliliters of trap solution and three boiling stones to the boiler.

3. Adjust the oxygen supply to permit a flow rate of about 370 milliliters per minute, then turn on the boiler heater and permit the solution to boil at a rate to yield about 180 milliliters of distillate per hour.

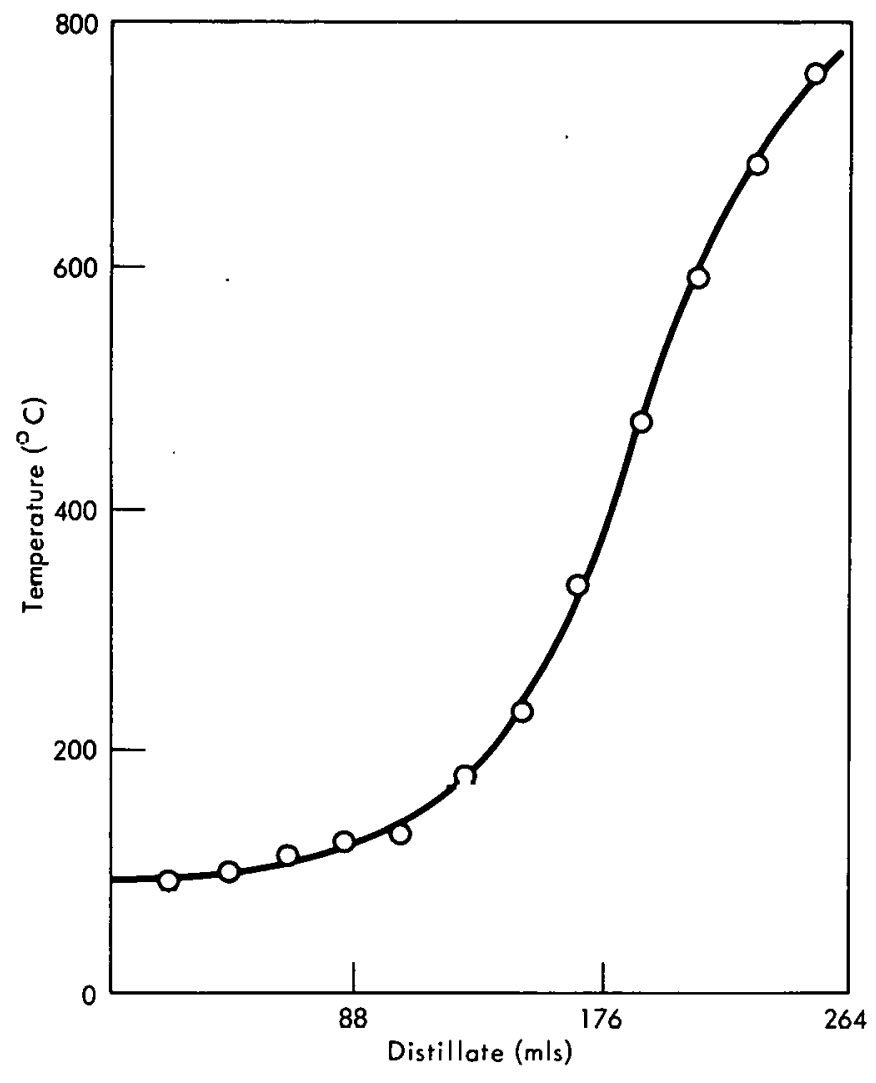

Figure 4. TEMPERATURE PROGRAM FOR THE STEAM DISTILLATION/PYROHYDROLYSIS OF RAFFINATE SOLUTIONS.

4. Adjust the Sigmamotor pump to permit the flow rate of the feed solution to equal the flow rate of the distillate, collect the trap distillate solution in about 50-milliliter fractions, and then analyze these fractions for nitric acid and hydrofluosilicic acid content.

\section{Raffinate Solutions}

Steps in the recovery of nitric acid from raffinate solutions are as follows:

1. Turn on Furnace B to medium intensity and permit the furnace to come to temperature.

2. Add about 500 milliliters of water and three boiling stones to the boiler flask.

3. Replace the feed delivery tube with a stopper and adjust the oxygen supply. to the boiler tube of the flask to permit a flow rate of about $\mathbf{4 0}$ milliliters per minute.

4. Turn on the boiler heater, permit the water to boil at a rate to yield 100 milliliters of distillate per hour, add about 20 milliliters of raffinate solution to the sample boat, and place the boat in the reaction tube zone to be covered by Furnace $A$.

5. Connect the condenser to its receiver and reaction tube, enclose the reaction tube with the upper part of Furnace $A$, and adjust its heat control to the lowest setting. 


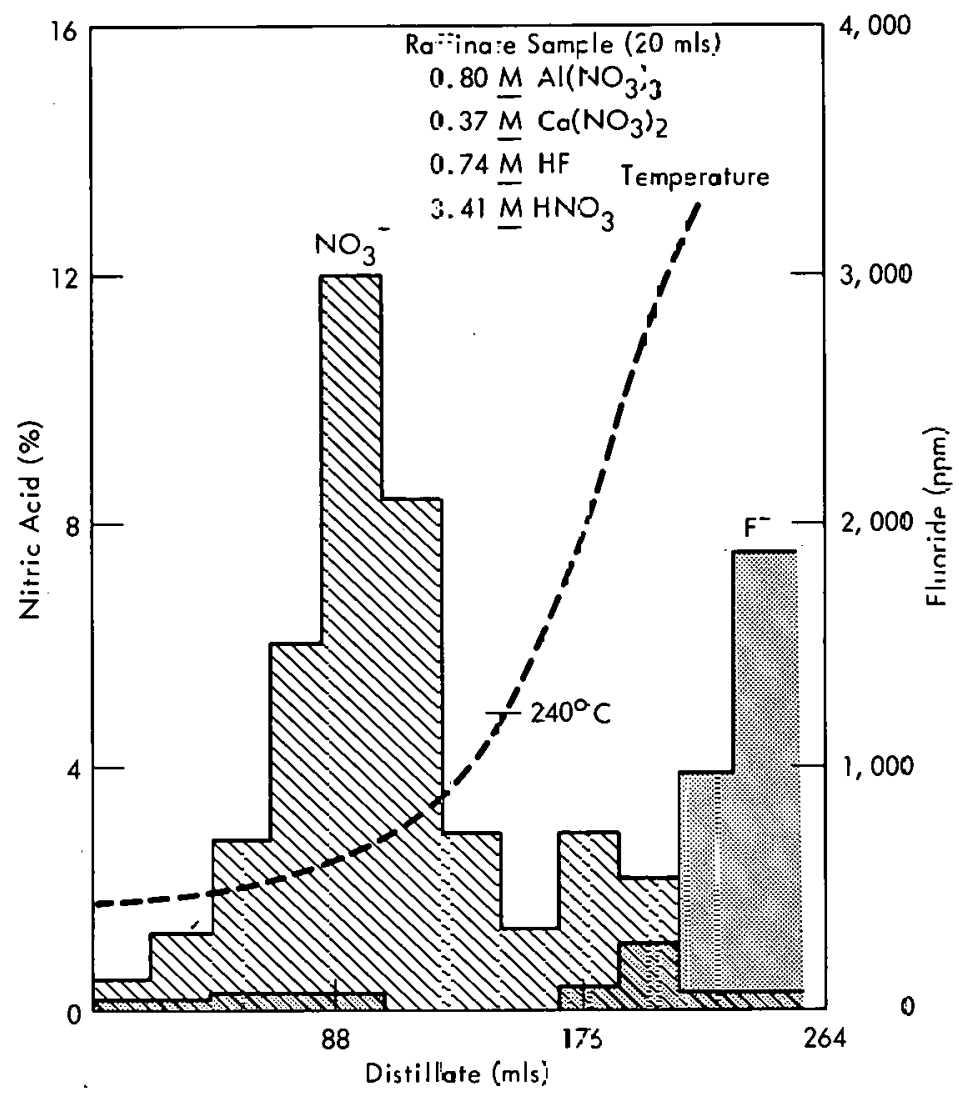

FigUre 5. STEAM DISTILLATION/PYROHYDROLYSIS OF RAFFINATE SAMPLE 1.

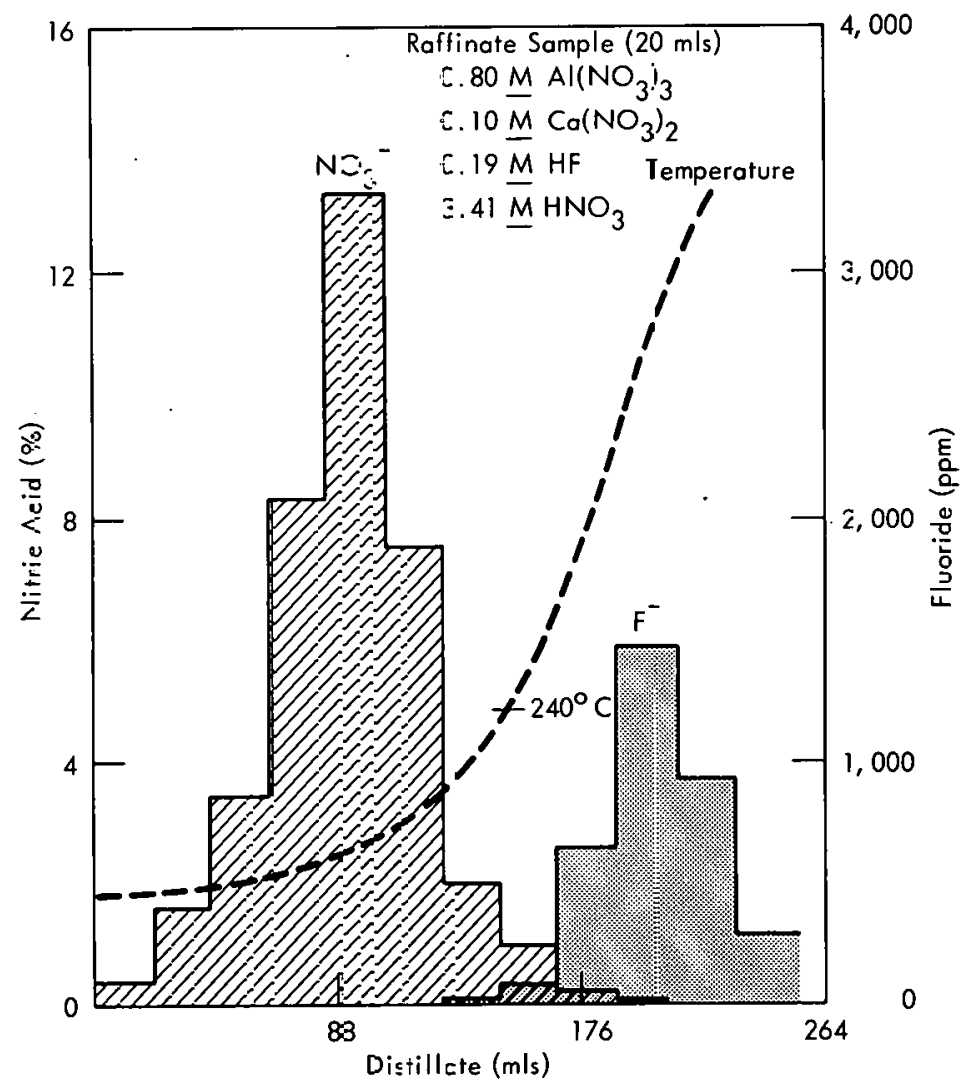

Figure 6. STEAM DISTILL.ATION/PYROHYDROLYSIS OF RAFFINATE SAMPLE 2. 
6. Collect the distillate in $\mathbf{2 0}$ - 25-milliliter increments and store for analysis.

7. Monitor the temperature of Furnace $A$ by observing the thermocouple meter reading (do not permit the temperature to exceed $100^{\circ} \mathrm{C}$ while the sample solution is present), then gradually increase the temperature of both Furnaces $A$ and $B$ to their maximum setting. (Please note that this operating procedure is suggestive and highly subject to change with the purpose of the experiment.)

\section{DISCUSSION}

\section{Condensate Feed Solutions}

The most practical approach to processing nitric acid condensate solutions, contaminated with chloride ions, appears to involve continuous distillation in an all-glass column. Useful guidelines for developing such a column can be derived from considering conditions for an ideal column. The distribution of nitric acid within an ideal column would be a concentration gradient from about $15.5-\mathrm{molar}$ acid at the bottom to about zero at the top. (1) An estimate of the rectification behavior of the chloride ion in this ideal column can be gained from a study of the nitric acid-hydrochloric acid-water vapor-liquid system at equilibrium and boiling at atmospheric pressure (Table 10). These equilibrium values are rarely attainable in any real column, but they are useful for estimating columnar performanice patterns. The vapor-liquid concentrations $(2)$ of chloride ion and nitric acid for Samples 1, 2, and 3 (Table 10) are each equivalent to one rectification unit or plate at 100 percent efficiency. Inspection of this vapor-liquid equilibrium data reveals a marked drop of chloride ion content in the vapor phase for decreasing nitric acid concentration in the liquid phase, while the chloride ion content in the liquid phase averages about 550 -ppm chloride over the range studied. With this ideal model as a guide, a preliminary study was initiated to investigate the rectification behavior of an actual laboratory-scale glass column.

A Raschig-ring-packed glass column was put into operation to process a 2.2molar nitric acid solution containing 200-ppm chloride ion. After about six hours, samples of the distillate, liquid zones within the column, and still liquid were collected and analyzed for their nitric acid and chloride ion contents (Test A, Table 1). A study of the data reveals a concentration gradient of nitric acid within the column, a chloride ion content of $0.1 \mathrm{ppm}$ for the 14-molar nitric acid still liquid, and $200 \mathrm{ppm}$ for the four-molar nitric acid distillate (Table 1). A high concentration of chloride in the condensate feed was selected to assure saturation of the system in minimum time.
Table 10

VAPOR-LIQUID EQUILIBRIUM FOR THE NITRIC ACID HYUROCHLORIC ACID-WATER SYSTEM

\begin{tabular}{clcc}
\hline Sample & Phase & $\begin{array}{c}\text { Calculated } \\
\text { Hydrochloric } \\
\text { Acid } \\
\text { Molarity }\end{array}$ & $\begin{array}{c}\text { Chloride Ion } \\
\text { Concentration } \\
\text { (ppm) }\end{array}$ \\
\hline \multirow{2}{*}{1} & Vapor (1) & 0.002 & 7 \\
& Liquid & 0.181 & 573 \\
2 & Vapor & 0.0289 & 9 \\
& Liquid & 1.815 & 508 \\
& Vapor & 0.450 & 247 \\
& Liquid & 4.870 & 582 \\
\hline
\end{tabular}

(1) Vapor in each sample was analyzed as the condensed liquid. 
An overall view of the previously mentioned experiment clearly reveals insufficient rectification power, since the desired situation would be 14-molar nitric acid in the still liquid and essentially water in the distillate. However, the survey might be extended by interrupting the fractionation at some point less than the steady state. With this point in mind, a rerun was made, this time sampling the system when the acidity of the distillate was about one tenth of the final distillate value for Test $A$. A study of the data for Test $B$ in Table 1 reveals a chloride ion content of $0.1 \mathrm{ppm}$ for the 12.5 -molar nitric acid still liquid and $200 \mathrm{ppm}$ for the 0.32 -molar nitric acid distillate. The data also reveal a concentration gradient of chloride ion and nitric acid within the liquid zones of the bed; but, as in the case for Test A, no significant buildup of chloride ion.

The Raschig-ring packing was replaced by more efficient single-turn helixes, and the condensate feed was introduced at room temperature into the center of the column to improve the separation by increasing the reflux in the lower portion of the column. (3) Also, about two inches of insulation was removed from the bottom of the column to further increase the reflux ratio in this strong acid zone. This modified column was then employed in continuing the investigation of the purification and concentration of nitric acid in these condensate feed solutions by distillation.

Sometimes these condensate feed solutions contain low concentrations of chloride and fluoride ions. Knowledge of the distribution of nitric acid and chloride ion, as well as fluoride as hydrofluosilicic acid in the glass column, was desired. The condensate feed was spiked with $200-\mathrm{ppm}$ chloride ion and $100-\mathrm{ppm}$ fluoride ion, and was added to the column until the distillate yielded 0.14 -molar nitric acid. The system was sampled and analyzed (see Test $C$, Table 1). The chloride-ion content of the still liquid and distillate was comparable to the previous runs, but significantly different within the liquid zones of the column bed. The total fluoride processed by the column appeared to be divided between the still liquid and the distillate. A second run was made, and the system was sampled at a distillate concentration of 0.008 -molar nitric acid. These samples were analyzed for chloride, fluoride, and nitric acid (Test D, Table 1). The chloride-ion content of the still liquid and distillate equalled Test $\mathrm{C}$, but significantly increased within the zonal regions of the column bed. An accumulation of chloride ion was also noted for Zones 2 and 3 . The fluoride in Test D showed a marked preference for the still liquid and clearly shows that fluoride concentration will build up in the still liquid when the distillate acidity approaches 0.01 -molar nitric acid.

The nitric acid rectification power or number of plates in the previously mentioned Raschig ring or helix-packed columns was estimated from the McCabe-Thiel diagrams. ${ }^{(4)}$ This estimation involved the insertion of graphically detcrmined operating lines into a vapor-liquid equilibrium curve for boiling nitric acid at atmospheric pressure and "stepping off" the plates with these guidelines on the vapor-liquid curve. (5) The operating lines were derived from a material balance of the nitric acid in the upper and lower half of the respective column. The number of plates for the columns was found to be about 2.5 for the Raschig ring and about 4 for the helix packings.

An estimate of the performace of a column having greater than four plates was hypothesized by arranging the results for Test $C$ as the lower and Test $D$ as the upper section of a larger column (Column CD). End effects of Tests $C$ and $D$ were excluded in this estimation of 
Column CD with the exception of Position 4 and the fluoride concentration for the still liquid of Test $D$ (Table 1). A study of the data assigned to hypothetical Column CD should provide a good estimate of the rectification behavior of nitric acid, hydrochloric acid, and hydrofluosilicic acid within a helix-packed all-glass column.

A general estimation of a concentration gradient for hydrofluosilicic acid within an ideal column could not be derived. No literature reference to the vapor-liquid equilibrium values for the hydrofluosilicic acid-nitric acid-water system at the boiling point and atmospheric pressure was available. Therefore, inspection of the data for hypothetical Column CD shows that the hydrofluosilicic acid preferentially flows toward the strong acid concentrations and accumulates in the still liquid. This distribution of hyrofluosilicic acid woul place limitations on the fluoride concentrations in the condensates in order to prevent excessive contamination of the still liquid. Confirmation of this fluoride distribution was essential, and a real column of equivalent length was constructed.

A condensate solution containing two-molar nitric acid and $400 \mathrm{ppm}$ of chloride and fluoride (hydrofluosilicic acid) was processed in a long column packed with glass helixes. The system was sampled and analyzed for nitric acid, chloride, and fluoride. The results are presented under Test $E$ (Table 1). A study of the data for Test $E$ reveals a rectification profile well supporting the distribution patterns of hypothetical Column CD.

Fluoride contamination in the condensate solutions cannot be removed from nitric acid by the glass rectification column. Analysis of actual condensate solutions from the solvent extraction process revealed about $0.2 \mathrm{ppm}$ fluoride which would yield about $1.2 \mathrm{ppm}$ fluoride as hydrofluosilicic acid in the still liquid. Since still-liquid contaminations of a few hundred ppm fluoride could be tolerated, no serious fluoride problem was anticipated; however, fluoride in the condensate solutions would require monitoring to assure operational limits. The better situation would be to incorporate an in-line purification unit to remove fluoride from the condensates prior to their entering the column.

\section{Chemical Trap Feed Solutions}

A promising purification scheme for nitric acid condensates, contaminated with fluoride, appeared to exist in a chemical trap where boiling solutions of aluminum and/or calcium nitrates would retain the fluoride and permit the acid to pass through the trap.

The major problem in achieving a practical chemical trap appeared to depend upon the acidity of the trap solution that would permit a continuous flow of two-molar nitric acid through the trap. A study of the vapor-liquid equilibrium system $(6)$ for nitric acid and water (Figure 7) revealed that a two-molar nitric acid distillate would require about an 8.6-molar nitric acid solution. A literature reference $(7)$ revealed that the nitric acid vapor-liquid equilibrium curve could be significantly shifted to the left of the 45-degree line (Figure 7) by a high concentration of a third component. Aluminum nitrate was selected as this third component, and preliminary single-batch distillations revealed that a boiling three-molar aluminum nitrate-one-molar nitric acid solution yielded a distillate of about 1.5-molar nitric acid.

A three-molar aluminum nitrate-one-molar nitric acid trap solution was prepared, and 275 milliliters of this solution were transferred to the boiler flask. The trap solution was heated 
to boiling, and a 1.5-molar nitric acid feed solution containing 200-ppm fluoride was fed to the trap. The trap distillate was collected in 55-milliliter fractions and analyzed for nitric acid and fluoride content (Table 2). A study of the data of Table 2 revealed about a hundredfold reduction of fluoride in the composited feed solution. During the purification, some hydrated alumina was observed. Since a stable trap solution was essential for a practical in-line unit, it was speculated that perhaps calcium nitrate could either provide an acceptable trap solution or a medium to stabilize aluminum nitrate.

A preliminary experiment with single-batch

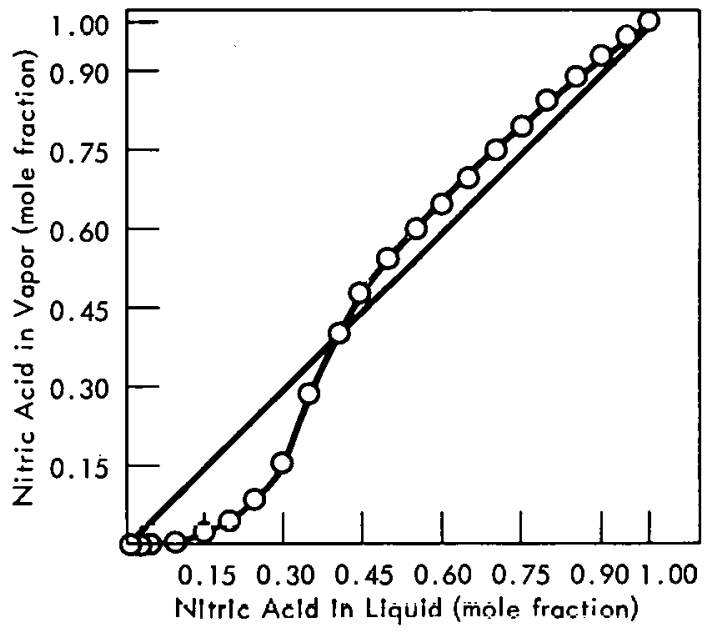

Figure 7. VAPOR-LIQUID EQUILIBRIUM SYSTEM. [Nhric Acid and Wateri; After Hoth and Scheos $(6)$ ] distillations revealed that a boiling six-molar calcium nitrate-one-molar nitric acid solution yielded a $1.8-\mathrm{molar}$ nitric acid distillate. A 212-milliliter aliquot of this calcium solution was transferred to the trap, heated to boiling, and fed by a 1.5 -molar nitric acid solution containung $200-p p m$ fluoride. The trap distillate was collected in 55-milliliter fractions, and some of the fractions were analyzed for nitric acid and fluoride content. The results of these analyses are presented in Table 3. Reference to Table 3 will disclose that the fluoride concentration in the purified feed solution averaged about $22 \mathrm{ppm}$ throughout the purification.

A comparison of the fluoride data for Tables 2 and 3 clearly shows aluminum's greater affinity for fluoride over the range of concentrations studied. Some performance estimate was needed to ascertain the trap capacity for much greater fluoride concentrations.

Trap solutions of three-molar aluminum nitrate-one-molar nitric acid and six-molar calcium nitrate-one-molar nitric acid were prepared. A 300-milliliter aliquot was taken from each solution, spiked with fluoride, heated to boiling, and a 21-milliliter distillate sample analyzed for fluoride content (Table 4). Reference to the data in Table 4 will again disclose the superior affinity of aluminum for fluoride. In the case of calcium, an explanation for a noticeable drop of tluoride concentration in the distillate with increasing concentration of fluoride in the still liquid is presently not known.

The experimentation just described revealed the feasibility of markedly depleting fluoride in 1.5-molar nitric acid solutions continuously passed through boiling trap solutions of three-molar aluminum nitrate-one-molar nitric acid and six-molar calcium nitrate-one-molar nitric acid. The next step appeared to mix the nitrates of aluminum and calcium to yield a trap solution having a very high salt content and resistant to the hydrolysis of the aluminum ion.

A trap solution was prepared by adding 546 grams of calcium nitrate, 246 grams of aluminum nitrate, and 14 milliliters of concentrated nitric acid to the boiler and heating the mixture to boiling. Feed solutions of one, three, and six-molar nitric acid containing 400-ppm fluoride and 22-ppm uranium were continuously cycled through the trap solution 
at 180 milliliters per hour. Vapors from the trap were condensed and analyzed for nitric acid, fluoride, and uranium ions. The results of these analyses are presented in Table 5. Uranium was not detected at the 0.04-ppm lower limit for the fluorimetric analysis.

A study of the data in Table 5 reveals that fluoride concentration in the output is largely dependent upon the acidity of the trap vapor phase or distillate fractions. For example, average fluoride values for the acid range studied were about $3 \mathrm{ppm}$ for 1.2-molar acid, 9.5 ppm for 2.3-molar acid, and $20 \mathrm{ppm}$ for 5.9-molar acid.

Insight into the mechanisim of this system required knowledge of the acidity of the trap liquid phases for the various acid feed solutions studied. Any direct analysis of free nitric acid in the trap solution was severely restricted by the strong concentration of aluminum nitrate, which would hydrolyze in any alkalimetric titration of free acid. Therefore, a careful accounting of all nitric acid, initially added to the trap mixture and entering and leaving the 450-milliliter trap solution, was made. The results of this accountability are presented in Table 6. A study of the data of Table 6 reveals good agreement of the vapor-liquid values for the first four cycles of the 1.03-molar feed and the first three cycles of the 3.01-molar feed. Average nitric acid values in the trap liquid were found to be 0.39 molar for the one-molar feed, 0.86 molar for the three-molar feed, and 1.73 molar for the six-molar feed. However, these trap acid values resulted in greater fluoride concentrations in the distillate solutions than anticipated from a careful comparison of the data in Tables 2 and 3 with the data in Table 5. A possible explanation to this apparent anomolous result might exist in the manner the feed solution was introduced into the $135^{\circ} \mathrm{C}$ trap solution.

That is, even though the feed solution entered far below the trap solution surface, a strong acid, as well as thermal gradient, would be expected in the immediate vicinity of the delivery tube exit. Thus, any undissociated silicon tetrafluoride and hydrogen fluoride in this rapidly changing region may not have time to fully dissociate into reactive species before escaping from the trap solution.

The concentration of such undissociated forms of fluoride must be reduced in the feed solution by limiting the acid concentration or the effective fluoride concentration in order to further deplete fluoride in the trap distillate. The effective fluoride concentration in the fccd solution could be readily reduced by adding some aluminum nitrate. I his latter route seemed more fruitful toward the development of a general fluoride trap.

Feed solutions of one, three, and six-molar nitric acid containing 400-ppm fluoride and 13 grams of aluminum nitrate per liter were cycled through the aluminum nitrate-calcium nitrate chemical trap of the composition previously described. The feed volume cycle was 330 milliliters for all acids processed except the six-molar feed and the immediately following one-molar feed which were $\mathbf{4 4 0}$ milliliters each. The trap distillate was collected in 55-milliliter fractions and analyzed for fluoride and nitric acid content. The results of these analyses are presented in Table 7.

A careful comparison of the data in Tables 5 and 7 reveals that acidity plays a markedly reduced role when aluminum is added to the acid feed. Average fluoride values in distillates from aluminum nitrate-containing acid feed were about $0.5 \mathrm{ppm}$ for the one-molar feed, $0.30 \mathrm{ppm}$ for the three-molar feed, and $1.6 \mathrm{ppm}$ for the six-molar feed. 
In the experiment just outlined, aluminum nitrate was added to the feed solution. In actual practice it would be advantageous to spike the feed solutions with a dilute aluminum nitrate-calcium nitrate solution proportional to the trap composition to maintain the integrity of the trap solution during processing of large volumes of feed.

This trap study clearly reveals the feasibility of realizing a unit process for continuously removing fluoride from dilute nitric acid solutions.

\section{Raffinate Solutions}

A scheme was desired for recovering nitric acid from solvent extraction raffinate solutions. These solutions essentially contain 0.3 to 0.8 -molar aluminum nitrate in 1.5 to 3.4 -molar nitric acid; and, occasionally, 0.1 to 0.37 -molar calcium fluoride. Separation of nitric acid from these raffinate solutions by distillation appeared attractive as a process if the decomposition of concentrated nitric acid into the oxides of nitrogen could be prevented. Since the oxides of nitrogen are converted to nitric acid by oxygen and water, it seemed reasonable that nitric acid in the presence of oxygen could be steam distilled. Also, continued heating of the raffinate residues in an oxygenated steam atmosphere should result in pyrohydrolysis of nitrate salts to hydrated oxides with the release of additional nitric acid.

An experiment was designed where synthetic raffinate samples could be steam distilled and their residues pyrohydrolyzed. Synthetic Raffinate Sample 1 contained 0.80-molar aluminum nitrate, 0.37-molar calcium nitrate, 0.74-molar hydrofluoric acid, and 3.41-molar nitric acid. Sample 2 contained 0.80-molar aluminum nitrate, 0.10-molar calcium nitrate, 0.19-molar hydrofluoric acid, and 3.41-molar nitric acid. A 20-milliliter aliquot of each raffinate sample was steam distilled/pyrohydrolyzed according to the procedure. The temperature of the sample area during this treatment is indicated in Figure 4. The distillate was collected in 21-milliliter fractions, and each fraction was analyzed for fluoride and nitric acid. The results are presented in Tables 8 and 9 and are plotted in Figures 5 and 6 . Fluoride results for Samples 1 and 2 reveal an average fluoride value for the first 168 milliliters of distillate to be 37-ppm fluoride for a 1:1 molar ratio of aluminum to fluoride in Sample 1 and 18-ppm fluoride for a 4.3:1 molar ratio of aluminum to fluoride in Sample 2. A summation of nitrate as nitric acid revealed a total nitrate recovery of 88 percent for Sample 1 and 95 percent for Sample 2. The remaining nitrate in each sample was recovered beyond the eighth distillate fraction, and the final residues contained $50-p p m$ nitrate each. A study of the symmetry of Figures 5 and 6 reveals that most of the nitrate in the raffinate samples was distilled as nitric acid at a temperature less than $240^{\circ} \mathrm{C}$, and that fluoride contamination of the nitric acid product is dependent upon the distillate volume. Reference to Tables 8 and 9 reveals a rapid increase in fluoride concentration as the aluminum in the residues becomes hydrolyzed. Fluoride, in the final residue was found to be 10 percent for Sample 1 and 0.08 percent for Sample 2.

An $X$-ray diffraction analysis of the final residues revealed only calcium fluoride because amorphous alumina could not be detected by $X$-ray diffraction. Therefore, it seems that the pyrohydrolysis converts aluminum nitrate and aluminum fluoride to a hydrated aluminum oxide and calcium nitrate to calcium oxide, while calcium fluoride is fairly stable. 


\section{CONCLUSIONS}

An overall view of the previous investigation reveals the versatility of the distillation process in purifying and concentrating nitric acid in condensate and raffinate solutions. In the initial studies, condensate feed solutions were processed in an all-glass rectification column to purify the nitric acid from chloride ions and concentrate the purified nitric acid. This glass rectification column resisted any corrosion by chloride ions but was vulnerable to fluorides which are sometimes in the condensate solutions. A preliminary study of the rectification behavior of fluoride-contaminated condensate solutions revealed that fluoride as hydrofluosilicic acid concentrated in the strong acid still bottoms.

Fluorides were removed from these condensate feed solutions by another distillation process where the feed solutions were continuously passed through a boiling aluminum nitrate-calcium nitrate trap solution. This trap also removed any metallic impurities, such as uranium, from the condensate solutions, and should also remove any sulfate and phosphate ions from condensate feed solutions due to the low solubility of their calcium salts. Finally, raffinate solutions were steam distilled and pyrohydrolyzed to recover most of the nitrates as nitric acid contaminated with fluorido.

In conclusion, a judicious combination of rectification column, chemical trap, and steam distillation/pyrohydrolysis would offer strong support to the purification and concentration of nitric acid from condensate and raffinate solutions. 


\section{REFERENCES}

(1) Whitman, L. S., Arnold, A., and Podlipee, F. J.; “Nitric Acid Recovery From Raffinate By Evaporation and Fractional Distillation", Journal of Chemical Enginnering Progress, pp 362-365; September 1956.

(2) Haggerty, P. F. and Hixon, A. N.; Report on Vapor-Liquid Equilibrium of Nitric Acid Solutions Containing Chloride Ion, TID-5146; University of Pennsylvania (1953).

(3) Robinson, C. S. amd Gilliland, E. R.; Elements of Fractional Distillation - Chemical Engineering Series, pp 125-127; McGraw-Hill Book Company, Inc. (1950).

(4) Ibid, pp 123-125.

(5) Crookes, R. C., Wilson, R. Q., Bearse, A. E., and Filbert, R. B., Jr; Composition of Vapors From Boiling Nitric Acid Solutions, Report BMI-978, p 7; Battelle Memorial Institute; rebruary $\overline{9}, 1955$.

(6) Roth, W. A. and Scheel, Karl; Landolt-Bornstein, Phsikalisch-Chemische Tabellen, pp 758-759; Funfte Umgearbeitete and Verhehrte Auflage, 1-Egranzung Band.

(7) Robinson, C. S. and Gilliland, E. R.; Elemēnts of Fractional Distllation, p 295; McGraw-Hill Company, Inc, New York (1950). 


\section{DISTRIBUTION}

Atomic Energy Commission - ORO

Hickman, H. D.

Zachry, D. S., Jr

Dow - Rocky Flats

Perry, C. C.

Oak Ridge Gaseous Diffusion Plant

Hartman, W. C.

Pashley, J. H.

Wilcox, W. J., Jr

Winkel, R. A.

Oak Ridge Y-12 Plant

Barkman, J. R.

Bernander, N. K.

Briscoe, O.W.

Burditt, R. B.

Burkhart, L. E.

Clark, F. E.

Denny, A.

Dietrich, W. C. (15)

Dodson, W. H.

Francke, H. C.

Gary, W. E.

Hurst, J. S.

Jeter, I, W.

Jones, F. W.

Kahl, K. G.

Keith, Alvin

Laggis, E. G.

Lundin, M. I.

Marrow, G. B.

McLendon, J. D.

Mee, W. T.

Morrow, R. W.

Napier, J. M.

Overholser, L. G.

Parsuris, J. A.

Phillips, L. R.
Rowan, J. H.

Sanders, M.

Schreyer, J. M.

Smith, H. F., Jr

Smith, R. D.

Speas, I. G.

Stein, P. E.

Strohecker, J. W.

Stroud, D. D.

Weathersby, W. E.

Whitson, W. K.

Williams, R. D.

Yaggi, W. J.

Y-12 Central Files (5)

$Y-12$ Central Files (master copy)

$Y-12$ Central Files (route)

Y-12 Central Files (Y-12RC)

Zucker, D.

Paducah Gaseous Diffusion Plant

Levin, R. W.

In addition, this document is distributed in accordance with the category UC-4, Chemistry, as given in the USAEC Standard Distribution Lists for Unclassified Scientific and Technical Reports, TID-4500. 